\title{
Test of ISO 52016-1 Energy Performance Of Buildings Calculation Procedure
}

\author{
Clemens Felsmann, Alf Perschk, Richard Franke \\ Technische Universität Dresden \\ D-01062 Dresden, Germany \\ clemens.felsmann@tu-dresden.de
}

\begin{abstract}
The European building performance directive EPBD is intending the implementation of an harmonized method for the evaluation of building energy performance. That is why a set of standards has been worked out addressing methods to calculate the performance of the building and its energy systems. In this paper the calculation method used to predict heat and cooling loads of the building and the indoor temperatures, respectively, has been analysed. Therefore the standardized calculation procedure has been implemented in simulation programme. The programme again has been verified to learn more about model accuracy, reliability and sensitivity. It was find from testing that model performance need to be improved. Also model accuracy is not satisfying.
\end{abstract}

\section{Introduction}

In (EPBD, 2010) it was requested, that the energy performance of a building shall be determined either on the basis of the calculated or actual annual energy that is consumed in order to meet the different needs associated with its typical use and shall reflect the heating energy needs and cooling energy needs (energy needed to avoid overheating) to maintain the envisaged temperature conditions of the building, and domestic hot water needs. The methodology for calculating the energy performance of buildings should take into account European standards; it should cover the annual energy performance of a building while accounting for differences at national and regional level, i.e. thermal characteristics of the buildings, heating and air-conditioning installations, application of energy from renewable sources, passive heating and cooling elements, shading, indoor airquality, adequate natural light and design of the building. Energy performance calculation can be applied to check the buildings consistency to any national minimum energy performance requirement. (EPBD, 2018) asks for an update of the general framework for the calculation of the energy performance of buildings to make sure appropriate implementation of energy efficient buildings. In particular it is requested that Member States shall describe their national calculation methodology following the national annexes of the socalled overarching standards, namely ISO 52000-1 (DIN Deutsches Institut für Normung e.V., 2017a), 52003-1 (DIN Deutsches Institut für Normung e.V., 2017a), 52003-1 (DIN Deutsches Institut für Normung e.V., 2017b), and 52016-1 (DIN Deutsches Institut für Normung e.V., 2015). The authors' main interest was to check both reliability and performance of the calculation methodology presented in ISO 52016-1 to figure out if this method could be applied as an easy to use and alternative method to complex buildings simulation, e.g. TRNSYS, E + or any similar simulation programme. This interest was intended by the fact that ISO 52016-1 offered a transient simulation on an hourly time step whereas former calculation methods were restricted to annual, seasonal or monthly balancing. In addition to that the availability of a simulation programme consistent to the standardized method would allow to run EPBD consistent calculation e.g. in the framework of legal certification.

Analysis so far is limited to the calculation of space heating demand. Any additional demand resulting from domestic hot water generation, losses caused by heating and cooling systems, and the dedicated use of renewable energy sources for heating and cooling purposes is not accounted for.

\section{(History of) Methods}

Two other calculation methods have been used before ISO 52016-1 has been published: EN 832 (DIN Deutsches Institut für Normung e.V., 2003) and ISO 13790 (DIN Deutsches Institut für Normung e.V., 2008). In EN 832 the following simple energy balance for the calculation of space heating demand $\mathrm{Q}_{\mathrm{h}}$ has been applied

$$
Q_{\mathrm{h}}=Q_{\mathrm{I}}-\eta Q_{\mathrm{g}}
$$

where $\eta$ is a factor accounting for any heat gain $Q_{g}$ reducing the heat losses $\mathrm{Q}_{\mathrm{I}}$. Heat losses and heat gains are balanced on either annual, seasonal or monthly basis having an impact on $\eta$ as well. ISO 13790 was including same formula for a monthly approach but has introduced a new simplified method based on hourly time steps. Transient building behaviour due to thermal mass effects have been taken into account in the calculation method by aggregating all effective thermal heat capacity of opaque walls into one capacity connected to a temperature $\vartheta_{\mathrm{m}}$, while $\vartheta_{\mathrm{s}}$ represents all surfaces including windows, see Figure 1. Surface temperature node $\vartheta_{\mathrm{S}}$ again is directly linked to the air temperature $\vartheta_{\text {Air }}$ node not depicted in the following figure. ISO 52016 now substitutes the simplified simulation approach of ISO 13790 by a new calculation method again based on an hourly time step but offering more 
transparency. The seasonal calculation method known from EN 832 and ISO 13790 has been deleted from standardization.

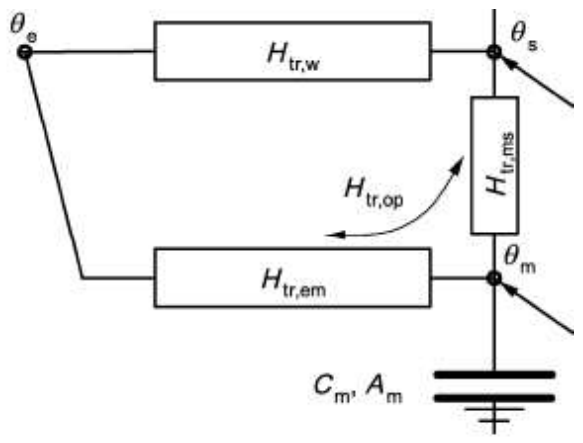

Figure 1: part of the ISO 13790 calculation model

Beside calculation method of ISO 52016-1 is embedded in the holistic EPBD calculation method. Finally the ISO 52016-1 method is an application of the generic method described in ISO 52017-1. A more detailed description and rationale of the method can be found in ISO/TR 52016-2. Main Intention of the hourly method is the opportunity to account for the impact of hourly and daily fluctuations of weather conditions, the operation (sun protection systems and blinds, thermostats, occupancy etc.) as well as their interaction with heating and cooling. Compared to the simple monthly calculation method only a few additional input data and model parameters shall be required to run the simulation. The basic modelling approach of ISO 52016 is related to the convective heat flow balance of thermal zone. That is why a building has to be divided into several of those zones. The energy balance of a single zone is as written in the Equation (2)

$$
\begin{aligned}
& \frac{\mathrm{C}_{\text {int }}}{\Delta \mathrm{t}}\left(\vartheta_{\mathrm{int,t}}-\vartheta_{\mathrm{int}, \mathrm{t}-1}\right)= \\
& \sum \mathrm{A} \cdot \mathrm{h}\left(\vartheta_{\text {int, }}-\vartheta_{\mathrm{s}}\right)+\sum \mathrm{H}_{\mathrm{v}}\left(\vartheta_{\text {int, }}-\vartheta_{\text {sup }, \mathrm{t}}\right)+ \\
& \sum \mathrm{H}_{\mathrm{tb}}\left(\vartheta_{\text {int, }}-\vartheta_{\mathrm{a}, \mathrm{t}}\right)+\mathrm{f}_{\text {int }} \Phi_{\text {int }}+\mathrm{f}_{\mathrm{sol}} \Phi_{\mathrm{sol}}+\mathrm{f}_{\mathrm{H} / \mathrm{C}} \Phi_{\mathrm{H} / \mathrm{C}}
\end{aligned}
$$

As to be seen from the equation zone internal temperature $\vartheta_{\text {int }}$ is changing from time step t- 1 to time step $\mathrm{t}$ depending on zone thermal heat capacity $\mathrm{C}_{\mathrm{int}}$, heat fluxes from walls and windows, ventilation air flow, thermal bridges as well as internal heat gains $\Phi_{\text {int }}$, solar heat gains $\Phi_{\text {sol }}$, and any heat or cooling load $\Phi_{\mathrm{H} / \mathrm{C}}$. The factors $f_{\text {int }}, f_{\text {sol }}$, and $f_{H / C}$ respectively define the convective portion of the total heat flows. For a given temperature heat and cooling load can be derived. Equation (2) could be easily solved as either heating and cooling load or internal set point temperature should be given and also all other variables are known in the time step $t$ but surface temperatures $\vartheta_{\mathrm{s}}$ do not. That is why surface temperature of the building envelope (external walls, windows, doors) as well as internal walls and ceilings have to be calculated as well. For building simulation programmes this approach in general is state of the art for decades and a lot of different approaches have been established to calculate transient heat flow through massive walls accounting for thermal heat capacity, solar absorption and long wave heat transfer between surfaces in detail. Nevertheless it is a new approach in a standardized calculation procedure as thermal mass of building envelope has been aggregated in single capacity as described before.

For calculation in the ISO 52016 framework opaque buildings elements (e.g. external walls) are characterized by two temperature nodes each placed on the internal and external surfaces of the wall as well as three nodes located inside the wall thus splitting the wall into four layers resulting in five nodes as shown in Figure 2. Internal zone and ambient temperature nodes are added for illustration.

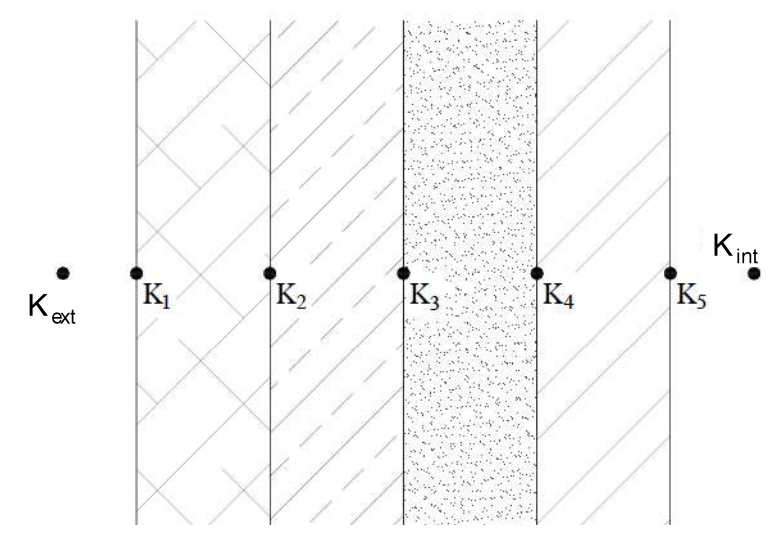

Figure 2: ISO 52016-1 model of opaque building element consisting of four layers and five temperature nodes $K$; internal and external nodes for illustration

It has to be mentioned that layers as shown in Figure 2 are more or less virtual layers just to be used to assign thermal capacity of the entire wall as well as heat flow resistances to the nodes and virtual layers. The assignment of heat capacity shall be done according to a fixed rule that again is referring to a classification of walls as described in the following Table 1.

\begin{tabular}{|c|c|c|c|}
\hline Class & $\begin{array}{c}\mathrm{K}_{\mathrm{m}, \mathrm{op}} \\
\mathrm{kJ} / \mathrm{kgK}\end{array}$ & Class & Specification \\
\hline $\begin{array}{l}\text { Very } \\
\text { light }\end{array}$ & 50 & I & $\begin{array}{l}\text { Insulation outside; } \\
\text { thermal mass inside }\end{array}$ \\
\hline light & 75 & E & $\begin{array}{l}\text { Insulation inside; } \\
\text { thermal mass outside }\end{array}$ \\
\hline middle & 110 & IE & $\begin{array}{l}\text { Internal insulation; } \\
\text { thermal mass balanced }\end{array}$ \\
\hline heavy & 175 & D & $\begin{array}{c}\text { no insulation; } \\
\text { thermal mass balanced }\end{array}$ \\
\hline $\begin{array}{c}\text { Very } \\
\text { heavy }\end{array}$ & 250 & M & thermal mass internal \\
\hline
\end{tabular}

Table 1: ISO 52016-1 classification of walls in terms of their thermal mass and heat capacity

By the way windows and doors are not split into layers just consisting of two nodes placed on the surfaces. 


$$
\begin{aligned}
& \frac{\kappa_{\mathrm{j}}}{\Delta \mathrm{t}}\left(\vartheta_{\mathrm{j}, \mathrm{t}}-\vartheta_{\mathrm{j}, \mathrm{t}-1}\right)= \\
& \left.\frac{\lambda}{\delta}\right|_{-1}\left(\vartheta_{\mathrm{j}, \mathrm{t}}-\vartheta_{\mathrm{j}-1, \mathrm{t}}\right)+\left.\frac{\lambda}{\delta}\right|_{+1}\left(\vartheta_{\mathrm{j}, \mathrm{t}}-\vartheta_{\mathrm{j}+1, \mathrm{t}}\right)
\end{aligned}
$$

\section{Programming}

The algorithm proposed in international standard ISO 52016-1 applicable to predict room temperature and/or space heating and cooling loads has been implemented using the QT-Library for C++ in combination with the integrated development environment QT Developper (The Qt Company, 2018). The model was set up as kind of software module or subroutine (called TYPE) to be integrated into an existing TRNSYS environment. That is also why input data as well as any model parameter have been taken from this already existing TRNSYSTUD software tool. Two different approaches have been programmed with respect to the multilayer walls:

- The first method is consistent to the algorithms described in ISO 52016-1 (DIN Deutsches Institut für Normung e.V., 2015). Building construction elements are subdivided into the four virtual layers as described before. Building physical properties are allocated to the layers following specific rules defined in the standard (i.e. classes and allocation, see Table 1). In the global equation system the coefficients of the unknown temperatures are sorted according to the nodes.

- The alternative method is accounting for the real number of layers the wall is built of. Also the building physical properties are more realistic. The coefficients of the unknown temperatures are sorted according to building construction elements.

The linear equation system is solved using a solver of the template-library Eigen3 (Eigen, 2018a). Eigen is a high-level-C++ library of template-headers for linear algebra, matrices, vectors, numerical solvers and other related algorithms. The solver ColPivHouseholderQR $<$ _MatrixType $>$ (Eigen, 2018b) has been chosen as an appropriate option because there are from the solvers point of view no restrictions in terms of the structure of the equatin system. And structure of the equation system is depending on the building structure, thus it will vary. The solver finds the solution of the system of linear equations by $\mathrm{QR}$ decomposition and column pivoting of a matrix A, see equation (3) (Eigen, 2018b). The QR decomposition is the decomposition of a matrix A into a unitary matrix $Q$ and the upper triangular matrix R. The column pivoting is changing rows in the matrix by dividing smaller numbers by bigger numbers (Bärwolff, 2016). This will result in stable solutions with a matrix coefficient $\varepsilon \ll 1$, that again will lead to a machine accuracy of $1 \pm \varepsilon=1$ (Meister, 2008). The decomposition of matrix $A$ into the permutation matrix $\mathrm{P}$, the unitary matrix $\mathrm{Q}$ and the upper triangular matrix $\mathrm{R}$ is realized by the householder transformation (Eigen, 2018b).

$$
\mathrm{AP}=\mathrm{QR}
$$

The QR decomposition by householder transformation requires $\frac{2}{3} \mathrm{n}^{3}+\mathrm{O}\left(\mathrm{n}^{2}\right)$ computing operations (Wick 2012). In addition to that column pivoting increases the number of computing operations.

\section{Model application}

The simulation programme that has been built as described before will be used to predict room temperatures and thermal loads according to the ISO 52016-1 standard but has to be checked for plausibility and reliability. Several validations tests and sensibility checks have been performed. Finally also a cross-check with the simulation programme TRNSYS-TUD (Perschk, 2010) has been done. In total the following test were carried out:

- Transient heat transfer through walls

The method to calculate the transient heat transfer through walls according to ISO 52016-1 is analysed using a validation test described in ISO 13791 (DIN Deutsches Institut für Normung e.V., 2005)

- Heat capacity classification

It is analysed if heat capacity classification described in ISO 52016-1 match real wall constructions.

- Heat capacity allocation

Different Multi-layer wall construction will be used to analyse, if heat capacity allocation proposed by ISO 52016-1 will lead to reliable results. More realistic heat capacity allocation to wall layers is used as a reference.

- Allocation of heat conductivity

Similar to the test before the impact of allocation of heat conductivity to wall layers according to ISO 52016-1 is analysed by comparing simulation results to a more realistic allocation of heat conductivity within the wall.

- Allocation of heat capacity- \& heat conductivity A test is done analysing the impact of both heat capacity and heat conductivity on building performance.

- Validation test procedure

The validation test procedure described in ISO 52016-1 has to be passed; consistency of simulation results with reference data given in the standard is checked.

- Cross-check with TRNSYS-TUD

The predictions reported from the ISO 52016-1 model will be compared to results from the TRNSYS-TUD simulation runs. Three different test are carried out: single zone, 2-zone, and singlefamily house.

- $\quad$ Performance testing

The cross-check with TRNSYS-TUD is used to do performance testing as well.

Some of the tests will be described in more detail in the next chapter and results will be presented 


\section{Results}

\section{Example 1: Heat transfer through walls}

Standard ISO 13791 is describing a procedure to validate simulation of transient heat transfer through opaque building construction elements. The test is asking for the step function response of the inside air temperature in a cubic space consisting of six identical walls each touching ambient air. Ambient air temperature is rising rapidly within the first hourly time step from $20^{\circ} \mathrm{C}$ to $30^{\circ} \mathrm{C}$. Inside air temperature has to be reported for 120 hrs to be compared to time discrete reference values at 2, $6,12,24$, and $120 \mathrm{hrs}$, respectively. Validation has to be done for four different wall types. Wall type 1 and 2 are single layer walls with different characteristics whereas wall types 3 and 4 are consisting of three different layers; .wall type 4 is a mirror image of wall type 3 . Figure 3 is illustrating the structure if the wall types.
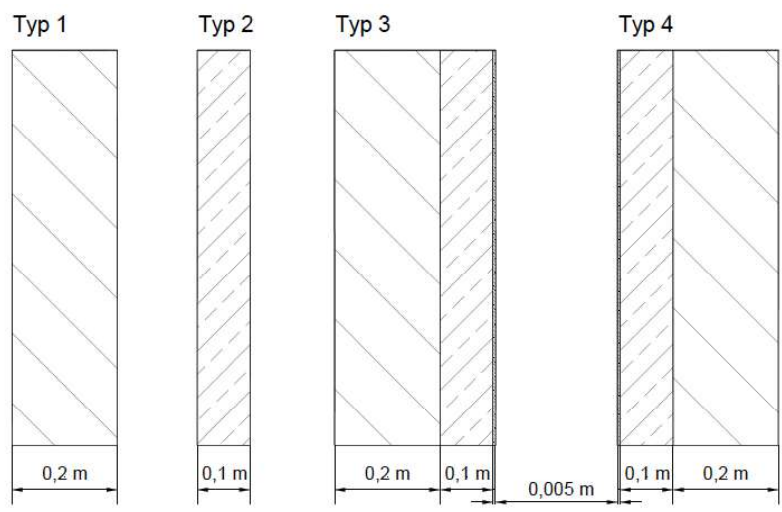

Figure 3: Wall types based on ISO 13791 validation procedure for heat transfer through walls

The validation is successfully passed in case the calculated room air temperature is deviating from the given reference temperature with less than $\pm 0.5 \mathrm{~K}$

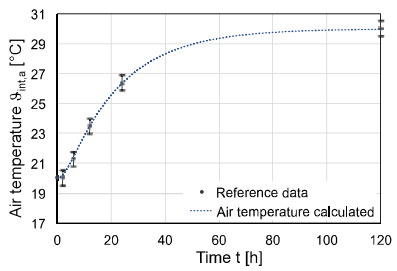

(a) wall type 1

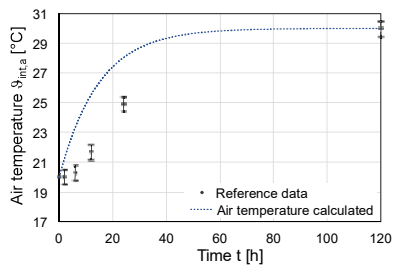

(c) wall type 3

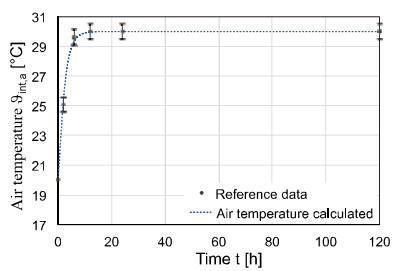

(b) wall type 2

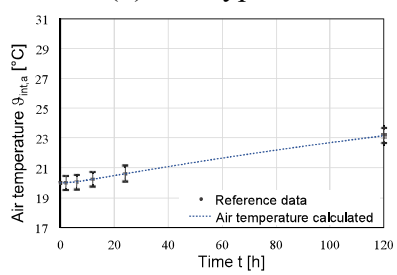

(d) wall type 4
Figure 4: Results of the heat transfer through walls validation test of ISO 13791 calculated with ISO 520161 building model

The diagrams in Figure 4 show that all wall types but wall type 3 passes the validation test: transient room temperature calculated with the ISO52016-1 simulation model are within the given error bands at given times it can be seen.It is astonishing that wall type 3 does not pas the test but wall type 4 do because type 4 is just a mirror image of wall type 3 . Further investigation is needed to figure out, what causes this noticeable behaviour.

\section{Example 2: Heat capacity classification}

Two different wall types are taken as a basis: a massive brick wall with insulation and drywall. Area related heat capacities of the walls are $545,000 \mathrm{~J} / \mathrm{m}^{2} \mathrm{~K}$ and 16,080 $\mathrm{J} / \mathrm{m}^{2} \mathrm{~K}$, respectively. Objective of the test is to figure out the sensitivity of predicted room temperature against heat capacity of the wall. Test condition is according to the Example 1. From Figure 5 illustrating the impact of heat capacity on room temperature step response it can be concluded that heat capacity classification as presented in Table 1 do allow a rough estimation of building performance as heat capacity of the building fabric has a significant impact on transient room temperature profile.

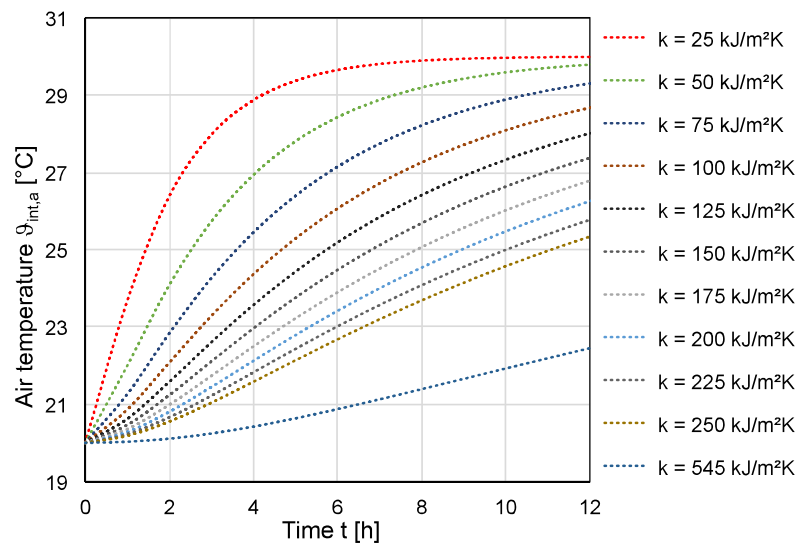

Figure 5: Step response of room temperature for different heat capacities in the wall

\section{Example 3: Verification of the full calculation} method

The verification of the full calculation method is targeting the operative temperature as well as the sensible heating and cooling demand for an entire year. The verification text cases requested in ISO 52016 are based on BESTEST $600 \mathrm{FF}$ and 900FF as described in ANSI/ASHRAE 140 (ANSI/ASHRAE, 2014). FF means free float, i.e. the free floating temperature caused by internal loads and ambient conditions have to be predicted. Obviously some specific adaptation have been done to fit the BESTEST to ISO 52016.

The different test scenarios are related to a simple building geometry just consisting of a single zone where two different types for the building envelope are used: a lightweight and a heavy eight building construction. Figure 6 is illustrating the view of the building. 


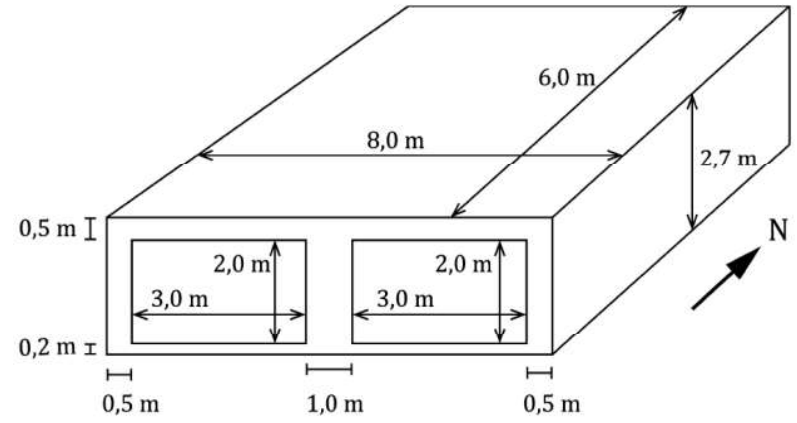

Figure 6: geometry of the ISO 52016 Test room taken from BESTEST / ASHRAE 140

To pass the verification the daily heating and cooling profiles as well as the operative temperature (i.e. the average of air temperature and radiant temperature) have to be predicted for both January 4 and July 27 . Results have to be compared with reference data. ISO 52016-1 does not offer reference data for July 27, that is why results for January 4 will be presented only. Daily profiles of operating temperature for both test cases (lightweight and heavy weight) are depicted in Figure 7.

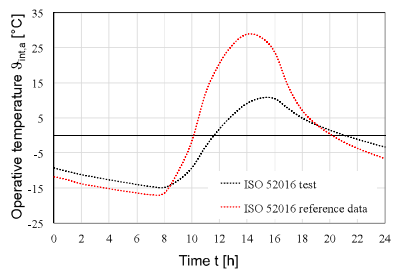

(a) light weight $(600 \mathrm{FF})$

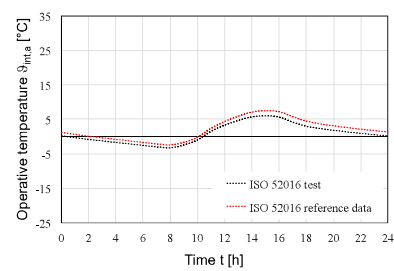

(b) heavy weight $(900 \mathrm{FF})$
Figure 7: Operative temperatures for ISO 52016-1 validation model (lightweight and heavy weight construction) January 4; heat capacity classes

From Figure 7a it can be presumed that overshooting of room temperature is cause by wrong allocation of building thermal mass. For that reason the real capacity following the given building fabric data rather than the heat capacity derived from wall classification (see Table 1 ) is used for further analysis. Finally for the lightweight construction this approach leads to much lower difference between predicted temperature profile and its reference, see Figure 8a. For the heavy weight construction in contrast the difference between prediction and reference is increasing when using more realistic heat capacity data rather than heat capacity classification, see Figure $8 \mathrm{~b}$.

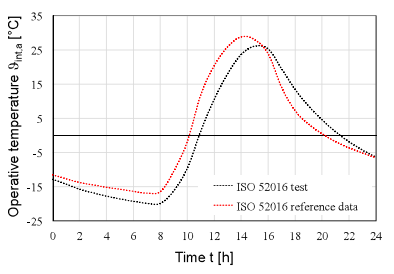

(a) light weight

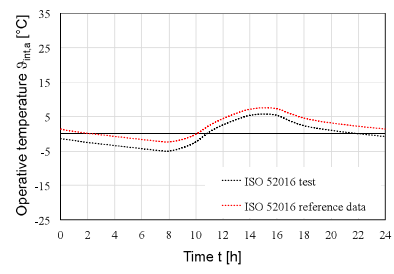

(b) heavy weight
Figure 8: Operative temperatures for ISO 52016-1 validation model (lightweight and heavy weight construction) January 4; real heat capacity

Another reason for discrepancy observed so far could be found in the modelling of the floor panel. In the validation procedure the floor panel is indirectly connected to ambient air temperature by adding an insulation layer in between. Normally ISO 52016-1 is using a so-called virtual ground temperature. Neither the standard ISO 52016-1 nor the accompanied technical report ISO/TR 52016-2 (DIN Deutsches Institut für Normung e.V., 2017c) are describing a method how to handle this approach.

\section{Example 3: Heat and cooling load / Energy demand}

For verification purposes annual heat and cooling loads have to be predicted. The monthly energy demand for heating and cooling is than be used as performance indicator. Again both lightweight as well as heavy weight construction will be analysed. In addition also set point temperature is modified, i.e. an invariable set point as well as an intermittent set point have been defined to estimate loads. Figure 9 is depicting the comparison of test results with reference data but for the lightweight construction only. The two diagrams in the top row of the Figure are related to fixed set point scenarios whereas the two graphs in the bottom row do show results for the intermittent heating and cooling cases. For plausibility it is noticed that intermittent heating and cooling leads to lower heating and cooling energy demands. The two diagrams in the left columns of Figure 9 present results of simulation runs which are done with an ISO 52016-1 model that is based on heat capacity classifications. As to be seen the ISO 52016-1 model using heat capacity classes is underpredicting heat and cooling loads. The application of more realistic heat capacities in line with the material characteristics lead to lower mismatch between test data and reference data.

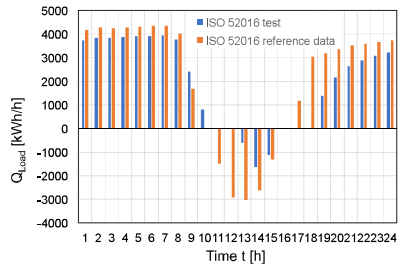

(a) fixed set point heat capacity classes

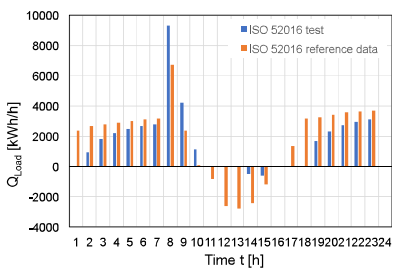

(c) variable set point

heat capacity classes

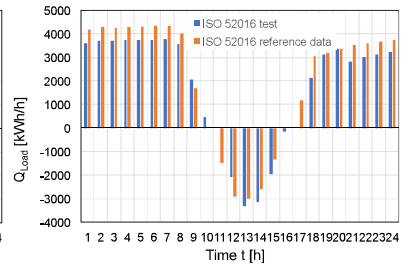

(b) fixed set point heat capacity real

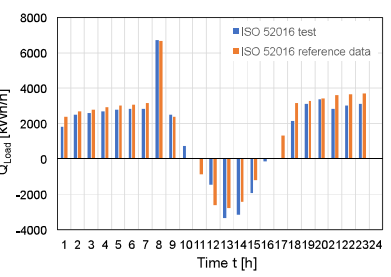

(d) variable set point heat capacity real
Figure 9: heating/cooling load profiles for the ISO 52016-1 lightweight construction test cases for steady state (top row) and intermittent (bottom row) set points, for heat capacity classes (left column) and realistic heat capacities (right column)

\section{Performance analysis}

Beside verification and validation also performance testing has been carried out. The laptop computer that has been used for that is specified as follows: 
Processor: i5-4210 CPU @ 1.70GHz

Main memory: 8,00 GB, DDR 3, $1600 \mathrm{MHz}$

System type: 64-Bit

Operating system: Windows 8.1 (Build 9600)

Software: Qt Creator 4.6.0 based on Qt 5.10.1 with MinGW w64 64bit (MSYS2)

Three different test cases have been analysed: single zone and 2-zone building as well as a single-family house. Run times have been determined for a single time step as well as for a full year simulation consisting of 8760 hourly time steps. Results of performance analysis are summarized in Table 2 . It has been recognized that both single zone and two-zone buildings can be simulated causing reasonable time effort whereas the single-family house was requesting two days of run time, which is not acceptable so far. Further optimization of computing is needed

Table 2: Run times ISO 52016-1 classification of walls in terms of their thermal mass and heat capacity

\begin{tabular}{|c|c|c|}
\hline \multirow{2}{*}{ Test case } & \multicolumn{2}{|c|}{ Run time in sec } \\
\cline { 2 - 3 } & $\square \square \square \square \square \square \square \square \square \square \square$ & 8760 time steps \\
\hline Single zone & $3.862 \times 10^{-2}$ & $1.073 \times 10^{2}$ \\
\hline 2-zone & $3.862 \times 10^{-2}$ & $3.383 \times 10^{2}$ \\
\hline $\begin{array}{c}\text { Single family } \\
\text { house }\end{array}$ & 19.54 & $1.71 \times 10^{5}$ \\
\hline
\end{tabular}

\section{Conclusions and Outlook}

The standard ISO 52016-1 does not give any statements about the quality of the results. Also simplifications regarding the calculation method (e.g. the classification of wall types and the allocation of heat capacities) make it difficult to evaluate the quality of the calculation results. The technical report ISO TR 52016-2 (DIN Deutsches Institut für Normung e.V., 2017c) is discussing the results of the validation test of ISO 52016-1 comparing it with the results of other software tools. From that it can be concluded, that the computational algorithm described in ISO 52016 results similar to other program should be generated. Nevertheless the simulations runs presented in this paper ask for further analysis of the code implementation with special focus on the heat capacity issue and run time performance.

Finally the full implementation of all other calculation methods described in a set of EPBD related standard is needed to allow the application of a standardized holistic approach for building performance evaluation.

\section{Nomenclature}

A area in $\mathrm{m}^{2}$

$\mathrm{h}$ heat transfer coefficient in $\mathrm{W} / \mathrm{m}^{2} \mathrm{~K}$

$\mathrm{H}$ heat loss coefficient in $\mathrm{W} / \mathrm{K}$

$\Phi$ heat load in $\mathrm{W}$

$\mathrm{C}_{\text {int }} \quad$ heat capacity in $\mathrm{kJ} /$

$\mathrm{Q}_{\mathrm{h}} \quad$ heat load in $\mathrm{W}$

Q $\quad$ heat losses in W

$\mathrm{Q}_{\mathrm{g}} \quad$ heat gains in $\mathrm{W}$ $\vartheta \quad$ Temperature in ${ }^{\circ} \mathrm{C}$

$\lambda$ heat conductivity in $\mathrm{W} / \mathrm{mK}$

$\delta \quad$ thickness in $\mathrm{mm}$

$\kappa$ heat capacity in $\mathrm{kJ} / \mathrm{kgK}$

$\Delta \square \quad$ time step in hrs

\section{References}

ANSI/ASHRAE (2014). Standard Method of Test for the Evaluation of Building Energy Analysis Computer Programs (ASHRAE-Standard 140-2014)

Bärwolff, G. (2016). Numerik für Ingenieure, Physiker und Informatiker. Berlin, Heidelberg: url: http://slubdd.de/katalog?TN_libero_mab23490662.

DIN Deutsches Institut für Normung e.V. (2015). Energy performance of buildings - Calculation of the energy needs for heating and cooling, internal temperatures and heating and cooling load in a building or building zone - Part 1: Calculation procedures (ISO/DIS 52016-1:2015); German version prEN ISO 52016-1:2015.

DIN Deutsches Institut für Normung e.V. (2003). Thermal performance of buildings - Calculation of energy use for heating - Residential buildings (DIN EN ISO 832:2003).

DIN Deutsches Institut für Normung e.V. (2008). Energy performance of buildings - Calculation of energy use for space heating and cooling (ISO 13790:2008); German version EN ISO 13790:2008.

DIN Deutsches Institut für Normung e.V. (2005). Thermal performance of buildings - Calculation of internal temperatures of a room in summer without mechanical cooling -General criteria and validation procedures (ISO 13791:2004); German version EN ISO 13791:2004.

DIN Deutsches Institut für Normung e.V. (2017a). Energy performance of buildings - Overarching EPB assessment - Part 1: General framework and procedures (ISO 52000-1:2017); German version EN ISO 52000-1:2017.

DIN Deutsches Institut für Normung e.V. (2017b). Energy performance of buildings - Indicators, requirements, ratings and certificates - Part 1: General aspects and application to the overall energy performance (ISO 52003-1:2017); German version EN ISO 52003-1:2017.

DIN Deutsches Institut für Normung e.V. (2017c). Energy performance of buildings - Energy needs for heating and cooling, internal temperatures and sensible and latent heat loads - Part 2: Explanation and justification of ISO 52016-1 and ISO 52017-1 (ISO/TR 52016-2:2017).

Eigen, (2018a). C++ template library. url: http://eigen.tuxfamily.org/index.php?title=Main_Pag e\#Overview (visited at 27.09.2018). 
Eigen, (2018b). Eigen. FullPivHouseholderQR. url: https://eigen.tuxfamily.org/dox/classEigen_1_1ColPi vHouseholderQR.html (visited at 31.07.2018).

EPBD, 2010. DIRECTIVE 2010/31/EU OF THE EUROPEAN PARLIAMENT AND OF THE COUNCIL of 19 May 2010 on the energy performance of buildings (recast). Official Journal of the European Union.

EPBD. 2018. DIRECTIVE (EU) 2018/844 OF THE EUROPEAN PARLIAMENT AND OF THE COUNCIL of 30 May 2018 amending Directive $2010 / 31 /$ EU on the energy performance of buildings and Directive 2012/27/EU on energy efficiency Official Journal of the European Union.

Meister, A. (2008). Numerik linearer Gleichungssysteme: eine Einführung in moderne Verfahren; mit MATLAB-Implementierungen von C. Vömel /. 3., überarb. Aufl. Wiesbaden: Vieweg,
2008. ISBN: 3834804312. url: http://slubdd.de/ katalog?TN_libero_mab214156701.

Perschk, A. (2010). Gebäude- und Anlagensimulation Ein Dresdner Modell. In: Gesundheits- Ingenieur Haustechnik - Bauphysik - Umwelttechnik 131.4 (2010), S. 178-183.

The Qt Company (2018). Qt Creator IDE. url: https://www.qt.io/qt-features-librariesapis-tools-andide/\#ide (visited at 25.09.2018).

Wick, T. and Richter, T. (2012). Einführung in die Numerische Mathematik. Ruprecht-Karls-Universität Heidelberg. 